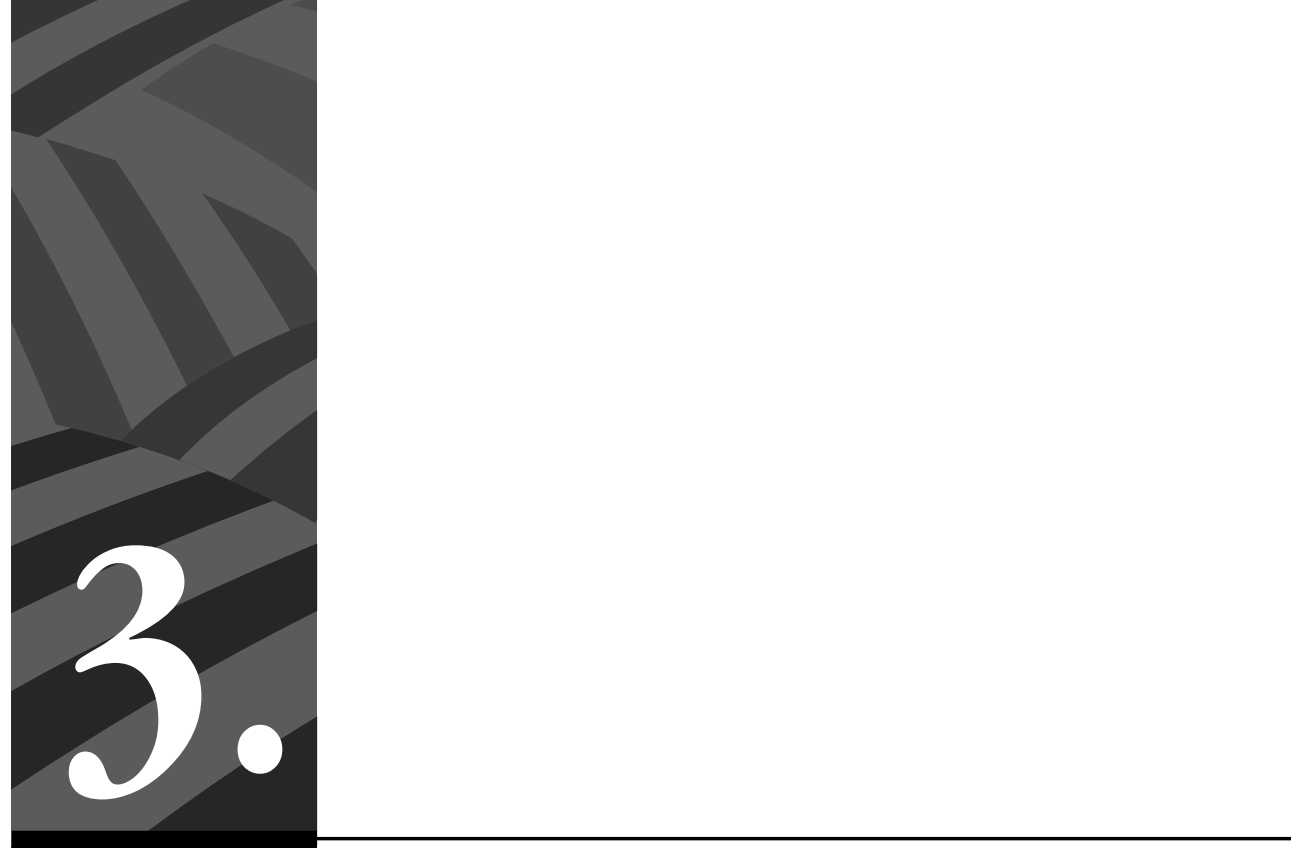

Localización y movimiento: estrategias de territorialización de la identidad afrodescendiente en Medellín 


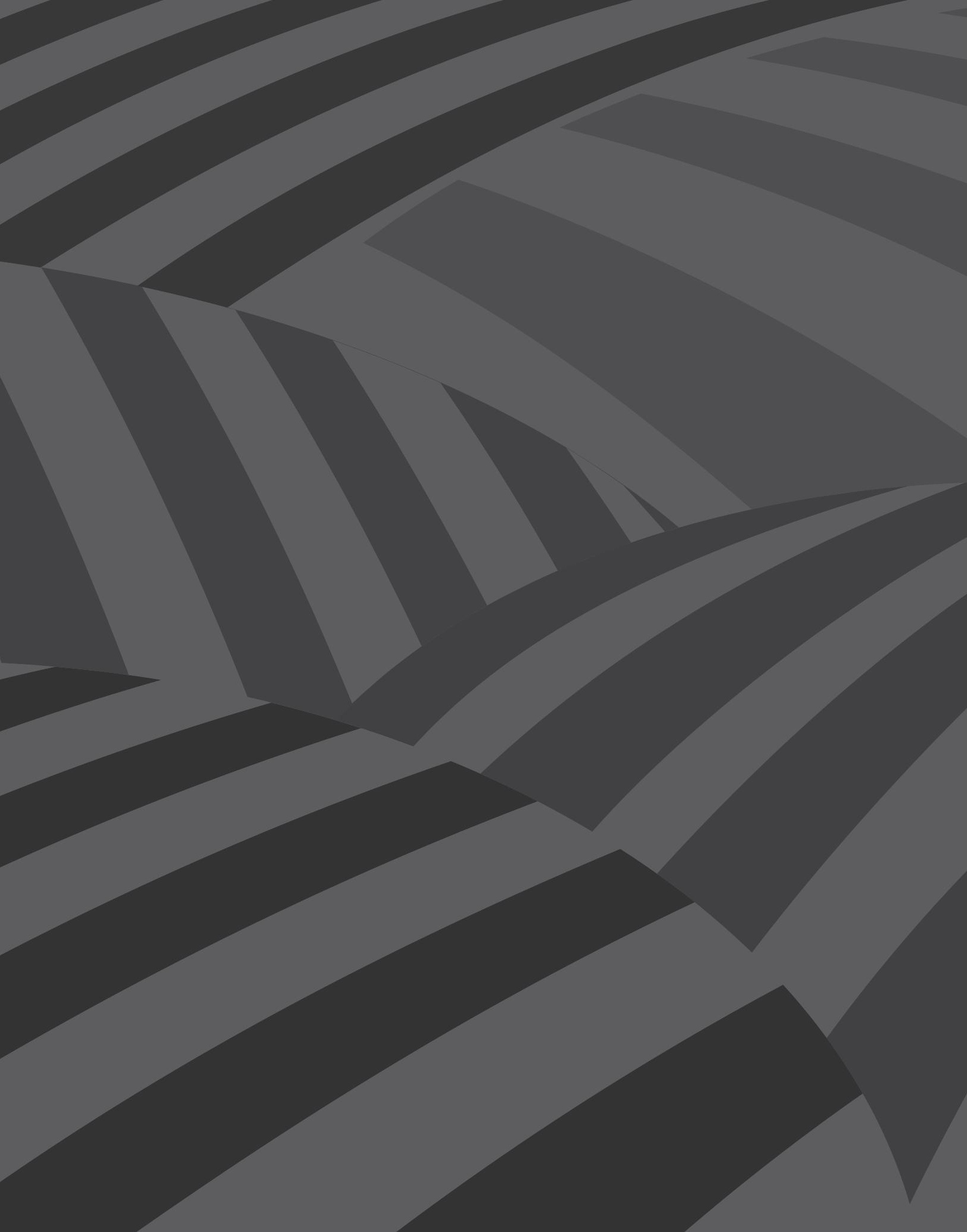




\title{
Localización y movimiento: estrategias de territorialización de la identidad afrodescendiente en Medellín
}

\author{
Por Ana María Restrepo Rodríguez*
}

Resumen: La reivindicación de la identidad afrodescendiente en la ciudad de Medellín ha sido, y sigue siendo, un largo proceso de disputa por la ciudad. Desde las décadas de los setenta y ochenta la percepción de una comunidad afrodescendiente, y por lo tanto de su diferencia, obligó a conformar lugares de socialización desde los que se empezaron a dar procesos de identificación y autorreconocimiento. En la década de los noventa y en años recientes, otras estrategias han hecho evidente la presencia y la disputa por el reconocimiento y el derecho a pertenecer: la movilización social y la fiesta irrumpen en el espacio público, activan campos de poder cultural e interpelan a los otros para reivindicar la diferencia, otras memorias de la ciudad y del ser medellinense.

Palabras clave: territorio, territorialidad, territorialización, identidad afrodescendiente, ciudad, movilización social, memoria, Medellín.

\section{Localization and Movement: Territorialization Strategies of Afro-descendant Identity in Medellín}

Abstract: The identity claims for the afro-descendant people in the city of Medellin has been, and it is still so, a long process of dispute for the city. Since the decades of the seventies and eighties the perception of an afro-descendant community, and therefore of its difference, forced to shape places for socialization. In these places the process of identification and self-recognition began. In the decade of the nineties, and in recent years, other strategies have made evident the presence of afro-descendant communities and its dispute for recognition and for the right to belong: social mobilization and celebration burst in the public space, activating fields of cultural power, claiming the difference to the-others, anothers memory of the city and about being a medellinense.

Keywords: territory, territoriality, territorialization, afro-descendant identity, cities, social mobilization, memory, Medellín.

* Historiadora y magíster en Estudios Literarios de la Universidad Nacional de Colombia y Maestra en Geografía Humana del Colegio de Michoacán, A. C. (México). Investigadora de la línea de Movimientos Sociales del Centro de Investigación y Educación Popular (Cinep), donde hace seguimiento a las acciones de lucha social del campesinado, indígenas, afrodescendientes, población desplazada y habitantes de frontera urbano-rural. Correo electrónico: arestrepo@cinep.org.co 
Cómo citar este artículo: Restrepo Rodríguez, Ana María (2019). Localización y movimiento: estrategias de territorialización de la identidad afrodescendiente en Medellín. Revista Controversia, 213, 103-144.

Fecha de recepción: 29 de marzo de 2019

Fecha de aprobación: 14 de junio de 2019

$\mathrm{E}$ 1 presente artículo $^{1}$ hace un recorrido por los escenarios y momentos claves de la disputa por el reconocimiento de una forma distinta de ser medellinense: serlo desde la afrodescendencia o la negritud ${ }^{2}$. Esto implica el desconocimiento o reconocimiento de los otros, la importancia de los lugares de encuentro, los impactos de acciones culturales y los procesos de movilización social.

\section{«Por aquí antes no había negros»}

Dos frases fueron recurrentes cuando en el año 2015 decía que estaba haciendo una investigación sobre afrodescendientes en Medellín. La primera respuesta de mis interlocutores (no afrodescendientes) solía ser: «iah, en el Parque de San Antonio!», un espacio público en el centro de la ciudad conocido por ser el punto de encuentro de las colonias

1 Este artículo es resultado de mi tesis de Maestría en Geografía Humana del Colegio de Michoacán (México): «Uno es de donde vive». Estrategias de territorialización de la identidad afrodescendiente en Medellín, 1970-2016. Investigación que adelanté entre los años 2015 y 2016. Disponible para consulta en: https://www.academia.edu/37432383/ Uno_es_de_donde_vive_Afrodescendientes_Medellin_AMRestrepo.pdf

2 A lo largo de todo el documento se usarán las categorías afrocolombiano y negro. En Medellín se autorreconocen como personas negras aquellas provenientes del Pacífico colombiano que no hacen parte de procesos políticos de diferenciación (demanda de una ciudadanía diferenciada) y algunos procesos de organización que han preferido «darle la vuelta» a la referencia al esclavo y apropiarse de él en el sentido del orgullo racial. La categoría «afrocolombiano» es usada para hablar del carácter nacional de este grupo étnico. Asimismo, es la forma que prefieren los participantes de procesos de organizaciones sociales que reivindican su identidad étnica por encima de la racial y en oposición al adjetivo «negro» que se relaciona con la memoria de la esclavitud (no se niega esta memoria, pero se prefiere rechazar el proceso). 
afrodescendientes, es decir, de los migrantes por lugar de procedencia. La segunda: «por aquí antes no había negros»³.

Estas ideas -la primera sobre un lugar-de-afrodescendientes y la segunda sobre un espacio que se fue llenando de unos otros- revelan la forma en que se han desarrollado procesos de apropiación identitaria del espacio público urbano, la invisibilización o negación de las múltiples identidades que conforman la vida de la ciudad y, finalmente, cómo se comprende la diferencia cultural a partir de su localización.

Medellín es una ciudad paisa. La paisa es la identidad cultural de una sociedad patriarcal, conservadora, católica, principalmente comerciante. Un paisa es una persona que habita en la región cafetera del noroccidente colombiano, mestizo, que come arepa, fríjoles y chicharrón, toma aguardiente, es el mejor conversador y donde sea pone un negocio, "porque un paisa no se vara». Es también exagerado. Tanto como lo es esta categorización.

En realidad, como toda comunidad imaginada (Anderson, 1993) lo paisa, más allá de lo discursivo, se reconoce en ciertas prácticas cotidianas, en hábitos comunes que se sustentan en la historia y que dan forma a la cultura. Por lo tanto, no hay tal homogeneización del habitante de Medellín. Muchos mestizos no se identifican como paisas, sino simplemente como medellinenses o antioqueños y muchos afrodescendientes o indígenas recogen hábitos paisas. Pero, en términos de identificaciones, para los afrodescendientes en Medellín lo paisa es aquello que representa la otra cultura del lugar que habitan y que es mayoritaria. Sienten esa diferencia en la comida, en el acento, en las relaciones interpersonales, en los referentes territoriales externos a la ciudad, en la participación en las fiestas y hasta en el campo de acción en términos de acción política4.

3 Valga la pena resaltar que esta frase se repite en otras ciudades, tal como lo señala el trabajo de Claudia Mosquera Rosero (1998).

4 En Gente negra, nación mestiza: dinámicas de las identidades raciales en Colombia, Peter Wade (1997) ha aportado una interesante definición de la identidad étnicoracial paisa desde el complejo y violento proceso de blanqueamiento. 
Un recorrido por la historia urbana de Medellín y sus procesos de espacialización de la diferencia muestra la necesidad de creación de estrategias de la población negra y afrodescendiente de la ciudad para estar en el espacio. Valga señalar que, desde el siglo XVII existen evidencias de presencia negra en lo que hoy se conoce como Medellín: en la reunión del 3 de enero de 1676, el Cabildo de la Villa de la Candelaria (Medellín colonial) expresaba su preocupación por el desorden del poblamiento urbano y construía una estrategia para garantizar un espacio acorde con las jerarquías sociales. Lo primero era que, en el centro de la ciudad, particularmente en los alrededores de la plaza principal (actualmente Parque de Berrío), no podían vivir más que los blancos ilustres. Así se determinó: «que los indios, mulatos y mestizos que vivan inmediatos a la plaza principal se retiren a los arrabales donde se les dé solares y los que tuvieren ocupados en lo inmediato a la plaza principal se repartan a las personas españolas y de más lustre» (Alcaldía de Medellín, 1676). Los mencionados arrabales eran la zona de Guanteros, de la que hablaré más adelante.

En el siglo XVIII, exactamente el 11 de octubre de 1757, es memorable la concesión de libertad que doña Javiera Londoño y su esposo don Ignacio Castañeda hicieron a todos sus esclavos con la condición de que visitaran su tumba. Por tomar esta decisión, un siglo antes de la abolición de la esclavitud, ella fue señalada como loca y tuvo que dar una dura pelea legal para que se respetaran sus deseos tras la muerte de su esposo.

En el siglo XIX el barrio Guanteros (el arrabal de la Colonia) se caracterizaba por ser lugar de artesanos, mulatos en su mayoría (Uribe, 1892, p. 79), artistas y bohemios que ya se diferenciaban de las élites blancas:

No fue extraño que descendientes de artesanos, como el ingeniero Alejandro López, se refirieran a los ricos de la ciudad como «la gente del marco 
de la plaza» y aún más acremente, como «los murciélagos ${ }^{5}$ y murciélagas blancas del marco de la plaza», revirtiendo así el estigma racial al que era sometido el estamento artesano (Mayor, 1996, p. 245).

En la transición del siglo XIX al siglo Xx las pinturas de Henry Price y los retratos de Melitón Rodríguez confirmaban estas presencias negras en la provincia de Medellín, como se puede apreciar en las figuras 1 y 2 .

Figura 1. Tipos de la Provincia de Medellín. Henry Price, 1852.

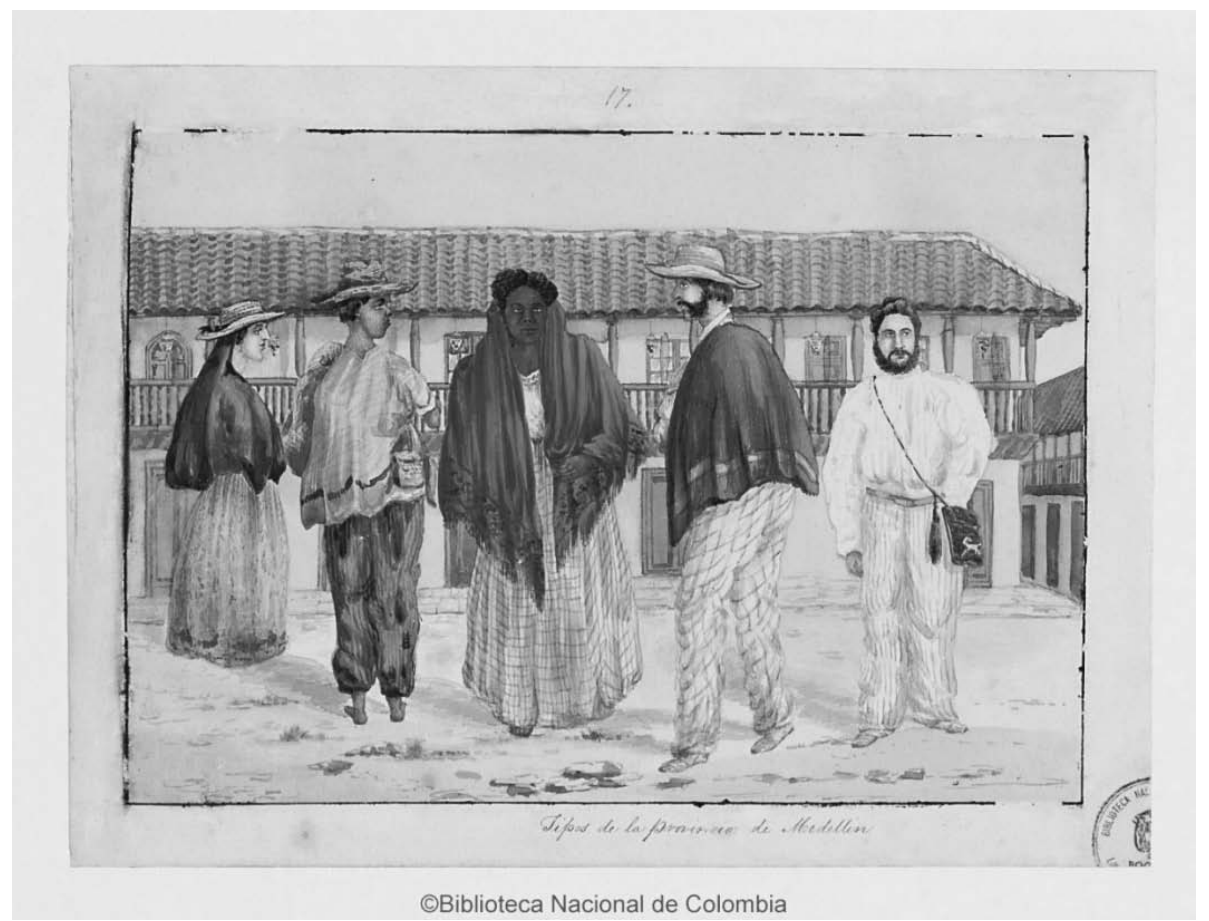

Fuente: Biblioteca Nacional de Colombia.

5 Habría que profundizar en este punto si la referencia al murciélago tiene que ver con sobrevivir a costa de los otros (chupando su sangre). 
Figura 2. Saturnina Rodríguez, Fotografía de Melitón Rodríguez, 1902.

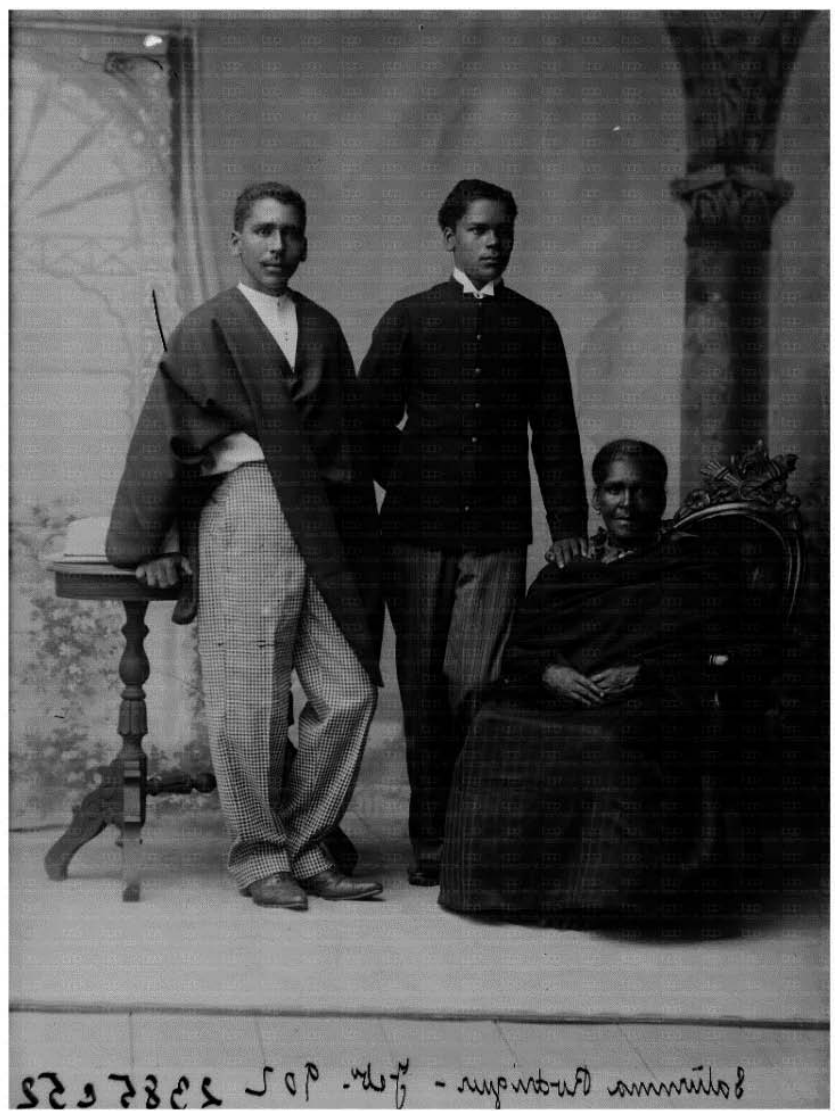

Fuente: Archivo Fotográfico, Biblioteca Pública Piloto, Medellín.

En la primera mitad del siglo xx un personaje de la vida cultural de la ciudad tan famoso como El Negro Cano confirmaba procesos de blanqueamiento que pasaban por la educación escolarizada y el estatus cultural. Antonio Jesús Cano no solo fue famoso por su librería ubicada en la calle 
Colombia con Carabobo, también fue presidente de la Junta Administradora del Instituto de Bellas Artes, que fue creado por la Sociedad de Mejoras Públicas, una agrupación de industriales y ricos que tuvo en sus manos durante este periodo la definición de la planeación urbana ${ }^{6}$.

Estas evidencias se entretejen con la historia de una ciudad que iba constituyendo su identidad como el paradigma de la ciudad moderna colombiana. Sin embargo, es a partir de los años setenta de ese siglo que dichas presencias pasan de ser un estar en la ciudad a convertirse en acciones de apropiación del espacio: reivindicación de una forma distinta de ser medellinense, ser negro o afrodescendiente y diferenciarse de lo paisa.

Si los habitantes de Medellín identifican el espacio del parque San Antonio con la comunidad afrodescendiente, están haciendo una espacialización que temporaliza su vivencia en la ciudad. El parque San Antonio fue construido en 1993. ¿Significa esto que antes la comunidad estaba dispersa? ¿O que no había personas negras en Medellín?

La reconstrucción de una cartografía de los lugares de memoria negra en Medellín no solo es relevante para la comunidad afrodescendiente, es también una revisión de la historia de la ciudad y un ejercicio de disputa de la memoria. En términos de Sarlo (2005), es la posibilidad de descubrir «en los pliegues culturales de toda práctica, el principio de afirmación de la identidad, invisible desde la óptica que definía una

6 La Sociedad de Mejoras Públicas fue fundada en 1899 por la élite empresarial y comercial del Medellín de fin de siglo. No solo se preocupó por el embellecimiento del espacio urbano, sino por la proyección futura del crecimiento de la ciudad. Con su poder económico y con la representatividad social de sus integrantes (entre sus más connotados estaban Ricardo Olano, empresario, transportista, dueño de la primera fábrica de fósforos, y Carlos E. Restrepo, presidente de Colombia en el periodo 1910-1914), logró convertirse en órgano asesor del Concejo de Medellín. De hecho, sus miembros pasaban a ocupar cargos en una y otra institución y en la oficina del ingeniero municipal. 
“vista del pasado" que privaba de interés [y de espacio] a la inventiva subalterna» (p. 18).

\section{El parque San Antonio, el lugar y el espacio}

Cuando el taxista lo dejó en el Parque de San Antonio, él le reclamó porque le había pedido que lo llevara al Parque de Bolivar.

El taxista simplemente asumió que, por ser negro, iba para el San Antonio

Notas de campo, febrero 25 de 2016.

La plaza de cemento con esculturas del artista Fernando Botero y el parque de la Iglesia de San Antonio están ubicados entre la avenida Oriental y la carrera Junín y entre las calles Bomboná y San Juan. La zona de espacio público fue hasta la primera mitad del siglo Xx un barrio en el centro de la ciudad; con la construcción de las avenidas (en ese afán de circulación en el centro que acabó con mucha de su unidad arquitectónica histórica) se desterritorializó a los habitantes del barrio y se fue convirtiendo en una zona abandonada. Durante mucho tiempo un cementerio de carros estuvo ubicado justo al frente de la iglesia. En 1989 se firmó el acuerdo metropolitano para hacer un parque en ese sector. Entre las propuestas de un espacio público tipo Central Park y un lugar de parqueaderos y fines comerciales se optó por la segunda, por razones de seguridad y beneficios financieros para la ciudad (Cardona, 2013).

Fue inaugurado en diciembre de 1994 con la instalación de algunas obras donadas por el artista Fernando Botero. El 10 de junio de 1995, durante el evento cultural Cartagena soy yo, explotó una bomba escondida en la escultura El Pájaro. Murieron 22 personas esa noche. El hecho fue atribuido al Cartel de Cali; era el tiempo de la guerra declarada al Estado colombiano por los carteles de droga y Medellín era el mayor escenario. Algunos dicen que fue luego de la bomba que los afrodescendientes empezaron a poblar el espacio de la plaza y sus 
locales. En los reportes de los muertos no hay indicadores raciales, porque esta es una variable que se ha implementado solo hasta los últimos años en el seguimiento a las víctimas de la violencia política y del conflicto armado en Colombia.

Actualmente todos los locales que rodean la plaza están ocupados por peluquerías, bares ${ }^{7}$ y restaurantes dirigidos a la población afrodescendiente. En los bares se reúnen de acuerdo a sus lugares de origen: la región del Urabá antioqueño, el departamento de Chocó, otros lugares del Pacífico colombiano, la región Caribe y municipios de la región del Bajo Cauca antioqueño. En las peluquerías se practican los tratamientos adecuados para el pelo afro y las trenzas o «tropas» que son peinados tradicionales (durante la Colonia, en la cabeza de mujeres y hombres, se diseñaban los mapas de fuga hacia los palenques). En los restaurantes se pueden consumir diferentes tipos de pescado traídos desde el Pacífico y otras comidas tradicionales.

En los relatos sobre el parque, se cuenta que es el lugar donde empiezan las relaciones sentimentales entre las empleadas del servicio doméstico y los trabajadores de la construcción o vigilantes nocturnos de los edificios. Allí se encuentran en sus tardes libres de domingo. Los sábados, aunque no hay espacios diseñados para los niños, las familias completas asisten al «ritual» del encuentro de cada fin de semana con sus paisanos. Es básicamente un espacio para el ocio. Los líderes de las organizaciones sociales con los que hablé no suelen ir a este lugar.

7 Es importante señalar que el otro espacio reconocido para la fiesta de los afrodescendientes en Medellín actualmente es la discoteca Jennylao. Está localizada en una de las zonas de rumba de la ciudad, la carrera 70. Pero esta no es accesible a toda la población por los altos precios de sus licores. En el mes de abril de 2016 la Fiscalía General de la Nación inició un proceso de extinción de dominio sobre la discoteca, pues al parecer su dueño creó esta fachada para los dineros que extraía de la Secretaría de Educación del vecino departamento de Chocó. 
Si bien el parque San Antonio produce marginalizaciones — como la idea del taxista de que una persona negra solo podría dirigirse allí-, su condición de lugar simbólico apropiado por los afrodescendientes de Medellín supera estas formas de exclusión. En primer lugar, no está cerrado al encuentro multicultural - aunque este no se efectúa-, y, en segundo lugar, en este espacio no se agotan las experiencias negras en la ciudad y mucho menos la identificación cultural.

En este orden de ideas, San Antonio representa a la vez la experiencia del lugar y del espacio. Para De Certeau (2000), un lugar es una configuración instantánea de posiciones, una indicación de estabilidad; el espacio, un cruzamiento de movilidades (p. 129). Esto no necesariamente implica que en el lugar no existan movimientos. El parque San Antonio representa la estabilidad de un sitio propio y la apropiación del espacio urbano. A través de las relaciones que allí se dan (entre «nosotros», con «los otros» y con la variedad de ese «nosotros»), ese lugar se transforma en espacio de la diferencia y ese espacio representa un lugar de prácticas cotidianas.

Según Doreen Massey (2012a), «los lugares raramente están libres de confrontación» (p. 259), se construyen políticamente. Valga aclarar que Massey usa el concepto de lugar como sinónimo de territorio, pero en este caso, por razones metodológicas y de escala, el lugar remite a la unidad mínima dentro de ese espacio que es objeto de disputa, el territorio. Es decir, entiendo en este caso a Medellín como territorio, pues es el espacio en disputa (necesario para la garantía del reconocimiento). Si bien esta disputa no apunta a la hegemonía de la identidad afrodescendiente, sí busca dispersar la idea unívoca de una identidad medellinense. Es este el sentido de territorializar la identidad: el proceso de apropiación del espacio urbano se ha ejercido no solo como arraigo (territorialidad), sino como arraigo desde unas prácticas culturales y unos sentidos de comunidad específicos. Dicho proceso se ha constituido a través de enclaves particulares (localizaciones como barrios, comunas, zonas, puntos de encuentro), pero sobre todo a través de 
la reivindicación de la pertenencia a ese marco amplio de la ciudad como medellinenses-afrodescendientes. Apuntan entonces a esa doble dimensión de la territorialidad: pertenezco a la ciudad y ella, a su manera, me pertenece.

Hecha esta aclaración, sigue vigente la idea de Massey (2012b) sobre la condición política del lugar. Si «el espacio es un producto de las prácticas, las relaciones, las conexiones y las desconexiones. Hacemos espacio a lo largo de nuestras vidas, y a todas las escalas» (p. 198). La multiplicidad que lo co-constituye y su contingencia suponen que un lugar como el parque San Antonio sea más que la localización de una anécdota: es el punto de llegada de otros lugares históricos del autorreconocimiento afrodescendiente, una más de las formas de territorialización de la identidad, un importante referente de su presencia en el espacio público y la materialización de cómo se explica (y se entiende) la diferencia a partir de su localización.

\section{La casa de las negritudes: Pablo Escobar Gaviria y la planeación urbana popular}

Bajando por la avenida De Greiff hasta la carrera Cúcuta y girando a la derecha, se encuentra en la mitad de la cuadra, sobre la acera oriental, la casa que Pablo Escobar donó a la comunidad negra de Medellín en 1984: la Casa de las Negritudes (actualmente sede de varias tipografías).

En las múltiples conversaciones que sostuve durante mi trabajo de campo, no hubo consenso sobre la función de la Casa. Para algunos era un centro de servicios médicos y odontológicos, para otros, un lugar para guardar instrumentos y para los ensayos de grupos de salsa y vallenato. Según doña Deyanira Valdés (Red de Mujeres Afrocolombianas Kambirí), allí funcionaba un centro de alfabetización para esa población negra que llegaba a la ciudad a trabajar en el servicio doméstico o en la construcción. 
Para Marino Rentería (director de la Corporación Afrocolombiana Malcolm X, consejero de Cultura y Comunicaciones del Espacio Autónomo del Movimiento Social del Pueblo Afrocolombiano de Medellín y director encargado de AfroMedellín), la Casa de las Negritudes tenía más carácter de oficina que de casa. Una oficina para el encuentro político de la comunidad negra de Medellín, que «hacía parte de un proyecto de Escobar de poner a los negros de su lado (...) Él quería organizar algo (...)» (entrevista, 19 de febrero de 2016).

La apertura de la Casa de las Negritudes se anuncia en la edición 1627 de Medellín Cívico, de enero de 1984, periódico de circulación mensual dirigido por Hernando Gaviria Berrío, tío materno de Pablo Escobar Gaviria y seguidor de la forma de planeación urbana de la Sociedad de Mejoras Públicas de Medellín (SMP). Dicha planeación era dirigida por la élite empresarial, que respondía a intereses particulares, y se desarrolló en muchas otras ciudades latinoamericanas durante finales del siglo XIX y la primera década del XX.

"Luego de un periodo “dorado”, desde inicios de siglo hasta finales de la década del cuarenta, la SMP sufrió un vertiginoso declive tras la compleja situación de crecimiento urbano que se presentó en Medellín» (Alzate, 2013, p. 106). Desde mitad del siglo Xx, se hacía imposible satisfacer las demandas de mejoramiento urbano y las necesidades de equipamientos para la población que iba llegando a la ciudad desde el campo. Además, la creación de las oficinas de planeación municipal en los sesenta, como respuesta del Estado al proceso de urbanización de la población, diezmó el marco de acción de la sociedad, con lo cual se convirtió en una institución más cercana a las obras de filantropía.

Si bien Hernando Gaviria Berrío no pretendía continuar la tendencia elitista de la SMP, sí consideraba necesario el espíritu cívico, el emprendimiento individual para el mejoramiento urbano y el ornato del espacio público. Así mismo, tenía una intención social: atender las demandas 
de los sectores populares en un contexto de precarización de sus condiciones de vida.

En la década de los ochenta Medellín se enfrentaba a ese proceso de urbanización que definía a las ciudades como sitios privilegiados del intercambio y la negociación. Era un nodo de conexión de sujetos, colectividades, gobiernos y medios, que a su vez derivan «en los distintos modelos de ciudad que se superponen en el espacio metropolitano» (Nivón, 2000, p. 115). Esta condición era resultado de los procesos de globalización que, al liberar el capital de escala mundial, necesitaban de las ciudades dada su posibilidad de articulación entre el centro y la periferia, entre lo local y lo global. Con ello, se modificaron las estructuras socioespaciales y se dio paso «a la transición del fordismo en combinación con una nueva forma de producción denominada postfordista, la cual se caracteriza por el trabajo intensificado y la producción por objetivos, ambos denominados flexibles» (Olivera, 2003b, p. 108).

Este proceso no solo modifica a Medellín como espacio urbano, sino que se espacializa en esta a través del cierre de empresas, del desplazamiento del centro económico de la industria textil por la economía de servicios, y, finalmente, impacta en el afán de sus administraciones en posicionarla como ciudad global.

No obstante, los estudios urbanos, concentrados en esta dimensión de la globalización, olvidan (o niegan) que un fenómeno social como Pablo Escobar también hace parte de la espacialización de la globalización, en dos sentidos. Por un lado, no hay que desconocer la globalidad de las economías del narcotráfico, su multiterritorialidad, sus redes y su condición transescalar, que recogen las condiciones de lo global - la circulación (de personas, bienes y capitales) y el intercambio (de productos, tecnología e información) (Olivera, 2003a) - y posicionan a la ciudad de Medellín en esa escala. 
Por otro lado, la transformación generada por la posibilidad o no de la concentración de la producción (de economías institucionalmente legales) «que repercute en los procesos de polarización social muy acentuados entre campo y ciudad, así como entre la población urbana» (Olivera 2003b, p. 120), hace parte del contexto en el que Pablo Escobar puede construir una base social para sus redes (económicas, políticas, de seguridad, etc.).

Tras veintiún años de ediciones, distribuidas en los barrios a través de los Centros Cívicos (que más tarde se transformarían en las Juntas de Acción Comunal), apareció en las páginas del periódico la voz de Pablo Escobar (diciembre de 1978). Medellín Cívico se convirtió en la mejor estrategia de legitimación de sus acciones, pues, desde 1977 y hasta 1984, su actividad con el tráfico de drogas $^{8}$ se ocultaba detrás de su vida política.

Las denuncias sobre sus actividades ilegales iban cerrando su capacidad de acción. El discurso cívico, herencia de su tío, le permitía fortalecer su imagen ante los sectores más pobres y criticar la desidia del Estado frente a los espacios en que estos habitaban. Para el caso específico de la Casa de las Negritudes, estaba aprovechando el desconocimiento de esta población en la ciudad para fortalecer su círculo de respaldo popular.

La edición en la que se anunció la apertura de la Casa de las Negritudes era un número especial (de quinientos mil ejemplares) que buscaba fortalecer ese respaldo a un personaje que meses después pasaría a

8 Durante el periodo 1977-1984, mientras que participaba en las elecciones al Congreso de la República y aparecía en los medios de comunicación, relacionado con personajes de la política nacional y del clero, Escobar «logró articularse a una red internacional de tráfico de drogas y su fortuna, producto del ilícito, empezó a crecer desmedidamente». Esta nueva fase del negocio se caracterizó "por la inversión de capital en distintos sectores económicos y la ausencia relativa de obstáculos en su accionar, a razón de la corrupción y el soborno a distintos representantes de los poderes públicos y las autoridades» (Alzate, 2013, p. 101). 
la clandestinidad. En las páginas de esta edición de enero de 1984 se evidencia cómo, con «Civismo en marcha», Escobar pretendía llevar a cabo un proyecto popular de planeación urbana alternativo.

«CIVISMO EN MARCHA», como lo saben los antioqueños, es una campaña cívica. Sin antecedentes registrados en América Latina ni el mundo. Generada por un hombre que ama en fuerte compromiso a su propio pueblo y que del mismo modo ha creado otros programas de acción social como «MEDELLÍn SIN TUGURIOS ${ }^{9}$ - un barrio de más de mil casas regalado a los tugurianos de la ciudad-, "LA CASA DE LAS NEGRITUDES» — una institución que desea recuperar los valores de la cultura negra y aglutinar las negritudes de la ciudad y el departamento para ofrecerles diferentes servicios gratuitos-. Estos son programas paralelos de gran impacto, que permiten un aporte real al desarrollo humano de Colombia. (Medellín Cívico, p. 2)

Dentro de su estrategia de «Civismo en marcha», Escobar celebraba encuentros semanales con los líderes comunales y sindicales para recoger las demandas sobre las necesidades de sus barrios. Estos encuentros eran transmitidos en directo por emisoras populares y concluían con la presentación de artistas que respaldaban esta «fiesta cívica», como la llamaba el periódico.

Según Medellín Cívico (1984), posteriormente se constituían los Comités Cívicos barriales a los que se asignaban los materiales y los asesores técnicos para «los trabajos que la misma comunidad realiza en el mejoramiento de su propio espacio». Mejoramiento y equipamiento de escenarios deportivos, adecuación de parques, construcción de escuelas y centros de salud y reparación de vías eran algunas de las obras adelantadas a través del programa. Escobar, además de ganar legitimidad

9 En Colombia se le dice tugurio tanto a la construcción hecha con latas, plástico, maderas y cartones con piso de tierra - característica de los destechados y de los desplazados recién llegados a las ciudades- como a los asentamientos conformados por estas construcciones. 
y poder territorial, denunciaba la «ausencia» del Estado en estos territorios populares y diezmaba su poder, pues pasaba por encima de la institucionalidad para cumplir los proyectos que emprendía.

De este modo, la idea de Marino Rentería, cuando señalaba que la Casa de Las Negritudes hacía parte de "algo que quería organizar Escobar», se explica como parte de un proyecto más amplio, en el que confluían sus intereses particulares de poder territorial, su «guerra» declarada al Estado (que luego se transformaría en una guerra armada) y su propósito de planeación urbana desde lo popular.

En la edición señalada, Escobar renunció a la vida política y afirmó que seguiría «en lucha franca contra las oligarquías y las injusticias sociales, y contra los conciliábulos partidistas» (p. 22). La Casa de las Negritudes se presentaba en el periódico como una obra de solidaridad con los habitantes venidos del vecino departamento de Chocó y como una forma de reconocimiento de su vivencia en Medellín:

La gente del Chocó vio siempre en las calles de la Ciudad de Medellín sus propias calles; en las universidades antioqueñas, las puertas abiertas para llevar su cultura; en miles de casas, fábricas y oficinas, la oportunidad para conseguir un trabajo (...).

Sin tener nosotros la evidencia de un racismo que discriminara los negros, la evidencia de la condición económica precaria que los azota ha establecido diferenciaciones, olvidos, discriminaciones que son intolerables. El negro se debate solo y de ahí que, como atraído por una fuerza imantada, se agrupe en lugares como el Bar Atlántico en pleno arrabal, o como las bellas terrazas del Banco de la República en pleno centro comercial. Allí dialogan entre sí, allí dan rienda suelta a su amor por la música; en el Banco de la República ven correr sus hijos al pie de bellos surtidores, lagos, arquitectura y mármoles que parecen hacer realidad el sueño de una vida mejor. Todo lo anterior la dura realidad lo rompe. Carece de atenciones mínimas en lo social. Los problemas laborales de las muchachas del servicio 
que ocupan gran parte de su gente, carecen de amparo. No hay quien les ayude a colocarse, a ingresar a una universidad, a protegerse de una enfermedad. Sus valores culturales grandes y bellos porque vienen saturados del toten [sic] ancestral del África misteriosa, milenaria y musical, vive a la deriva.

Buscando darles un punto digno de reunión. Organizarles colaboraciones médicas, jurídicas y laborales expresar su cultura autóctona en su propio medio ambiente, pero con el brazo amistoso e igual de personas que no son de su raza originaria ni de su color pero que sí tienen el mismo espíritu, la misma raíz patria y el mismo amor colombianista, se fundó la CASA DE LAS NEGRITUDES. (p. 22)

La importancia de la Casa de las Negritudes como lugar de memoria de la territorialización de la identidad afrodescendiente en Medellín radica en que este espacio fue la representación del reconocimiento de los habitantes negros de Medellín desde un actor no-negro. Pero, además, ese actor externo dejaba evidencias para la historia de las vivencias cotidianas de esa población al relatarlas por primera vez en un medio de comunicación público: lugares de encuentro (localizaciones en la ciudad), formas de supervivencia (opciones de trabajo) y necesidades sociales. Si bien es posible que la nota fuera escrita por uno de los líderes negros del proceso de instalación de la Casa, el respaldo del periódico entero y su inscripción en una edición especial que buscaba reivindicar el nombre de Escobar (cuando estaba siendo acorralado por las denuncias en su contra) representan una acción de reconocimiento de la presencia negra en la ciudad. Sobra decir que, asimismo, es el reconocimiento por parte de un actor que partió la historia de la ciudad en un antes y un después.

La historia de una ciudad planeada con el dinero del narcotráfico no se ha contado, en parte porque es una historia dolorosa y sustentada en otros valores. David Harvey (2014) es reiterativo en que «la cuestión de qué tipo de ciudad queremos no puede separarse de la cuestión de 
qué tipo de personas queremos ser, qué tipos de relaciones sociales buscamos, qué relaciones con la naturaleza valoramos, qué estilo de vida deseamos, qué valores estéticos sostenemos» (p. 273).

En ese orden de ideas, la negación o el ocultamiento de esa parte de la historia de Medellín tiene sentido, porque se sustenta en construir una ciudad sin miedo; sin embargo, con esa negación se diluyen otras trayectorias y otras historias importantes sobre la multiplicidad de esta ciudad. Este es realmente un desafío para una ciudad identificada con la innovación, la educación y la industria. Frente a esto, Eduardo Nivón Bolán (2000) propone un interesante ejercicio de interpretación: entender a la ciudad no como un lugar, sino como un proceso de multiplicidad cultural, de lo metropolitano como tensión entre el centro y la periferia y de globalidad expresada como intervención en lo local (p. 118).

\section{El San Pachito: la construcción contingente de un espacio de poder cultural}

Un automóvil blanco con una estatua de san Francisco de Asís en el techo. Grupos de gente negra con camisetas con frases que distinguen a cada grupo. Bailarines de comparsas. Una orquesta de chirimía no deja de tocar y jóvenes y adultos bailan y juegan con sus cuerpos. Un grupo de jóvenes mestizos de las juventudes franciscanas ${ }^{10}$ sentados en el piso sostienen carteles que demandan derechos sociales para el pueblo afrodescendiente. Música. Ropa muy colorida. Las bocinas de los carros resuenan porque esta gente ocupa cada vez más la calle y bloquea el tráfico. Venta de cerveza. Ruido y movimiento.

Todo esto sucede a las afueras de la sede de la Asociación de Institutores de Antioquia (Adida), en el centro de la ciudad de Medellín. Son las

10 Jóvenes que participan de grupos parroquiales confesionales, seguidores de las enseñanzas de san Francisco de Asís, y que eventualmente pueden ser las nuevas vocaciones de la orden franciscana. 
once de la mañana del quince de octubre de 2016, todos esperan que empiece el desfile «Entre bullas y tambores», el evento principal de las fiestas de San Pacho en Medellín.

Cuando la dirección de tránsito de la ciudad bloquea el paso de los carros de la calle Girardot, la gente se organiza para tomarse la calle. Encabeza el desfile la estatua de san Francisco, le siguen un par de comparsas y luego «el revulú». Minutos antes, un joven que me vio tomando fotografías me pregunta si vengo en grupo. Le cuento de mi trabajo de investigación y él me empieza a explicar que en las fiestas de San Pacho eso de las comparsas es «lo caché»", que lo realmente interesante es el revulú, la parte final del desfile conformada por «los que no vienen a mostrarse en comparsas, sino a la gozadera» (Notas de campo, octubre 15 de 2016).

Él viajó desde Apartadó (un municipio de la región del Urabá antioqueño) solo para esto. Me dice que el sonido del bunde (que incluye la música, la formación en grupo, el tipo de baile y la acción de ir recorriendo las calles mientras se baila) lo llama, que cuando era más pequeño y vivía en Quibdó se escapaba del colegio para irse a bundiar ${ }^{12}$. Ni siquiera puede explicarme con palabras lo que siente, sonríe, cierra los ojos y hace como que se le revuelve el corazón cuando empieza a sonar la chirimía ${ }^{13}$.

11 Lo refinado.

12 Las fiestas de San Pacho de Quibdó fueron estudiadas por primera vez por el antropólogo chocoano Rogerio Velásquez, en 1960. En su definición, el bunde consiste en «aglomeraciones apretadas de negros y negras que desfilan por las calles al son de chirimías y tambores» (Velásquez, 2010, p. 23).

13 Instrumento de viento de madera, parecido al oboe. En el Pacífico colombiano la chirimía da nombre tanto a un estilo musical como al grupo que lo ejecuta. Las chirimías, con sus instrumentos de viento y percusión, se desplazan por las calles durante las fiestas populares y son el centro de los bundes. 
Las fiestas de San Pacho son conocidas en Colombia por ser la celebración del santo patrono de Quibdó (Chocó). Cualquier referencia a estas fiestas en otras ciudades de Colombia se asocia a las colonias chocoanas en esas ciudades. Es decir, son una de las características principales de la identidad afrodescendiente de acuerdo a las localizaciones identitarias. En Medellín se celebran desde el año 1997 y su origen no fue solo la celebración de una fiesta añorada por los profesores de colegios de Medellín provenientes de Chocó: tenía la intención de socializar las prácticas culturales y establecer un diálogo multicultural.

El San Pacho en Medellín surge como un espacio de integración y de apropiación política y participación en los espacios de ciudad. Había muchos ejercicios que se venían haciendo y siempre se reducían a hacer guetos: Palacé, por la flota allá por la Secretaría de Educación, por aquí en Berrío y ahora el parque San Antonio. (Entrevista, 27 de enero de 2016)

Es una fiesta con específicas condiciones identitarias, que irrumpe en el espacio urbano, que se toma el centro de la ciudad y visibiliza la presencia y la cultura de la comunidad afrocolombiana en Medellín. Con su recorrido y con su persistencia a través del tiempo, ha ido territorializando una práctica cultural asociada a otro territorio (Chocó). Valga aclarar que se entiende aquí territorialización como la manera en que se va logrando la apropiación espacial de modo estratégico con el fin de alcanzar el reconocimiento de una territorialidad.

El San Pachito (como se le dice a la fiesta en Medellín) es una marca más para el proceso de memoria y de territorialización de una ciudad que ha construido su historia a partir de la voz de una sola identidad. En esa Medellín que pretende ser global se filtran, emergen y se conforman lo que Soja (2008) denomina «fuerzas de resistencias compensatorias (...) que reafirman $y$, frecuentemente, reordenan las diferencias culturales, volviendo a afirmar el poder de las culturas e identidades políticas heterogéneas» (p. 301). 
El recorrido del San Pacho y su impacto en el espacio público configuran por unas horas un nuevo centro identitario de la ciudad, a la vez que hacen que el centro de Medellín sea distinto (figura 3). Desterritorializa lo paisa y territorializa lo afrodescendiente. Es un centro que se mueve a otros ritmos, que asigna lugares a las identidades y las interpela. Es lo que Homi Bhabha (2002) llama un momento político de la diferencia cultural (p. 122). Por eso es también fundamental que esta fiesta no se haya trasladado a los barrios, lugares donde también se efectúan múltiples procesos de territorialización que dan sentido a la vida en la ciudad, pero que tal vez se quedan cortos en la apropiación de Medellín, de esa idea de pertenencia y derecho sobre una ciudad.

La potencia del San Pachito es que hace tangibles y pensables otras territorialidades medellinenses. Si un turista llega al centro de la ciudad durante este desfile, podría encontrarse con el poder de una comunidad afrodescendiente frente a unos cuantos mestizos que tímidamente se mueven y observan a lado y lado de las calles o desde los edificios; esa acción de solo dejar pasar habla del desfile como un espacio de poder cultural.

Quiero llamar la atención sobre el San Pachito como espacio de poder cultural y de interpelación de la diferencia. En Medellín se desarrollan distintos eventos afrodescendientes a lo largo del año, algunos organizados por la Alcaldía, pero ninguno tiene una capacidad de convocatoria como el San Pachito. Incluso, en la Feria de las Flores, la fiesta medellinense de cada agosto, se desarrolla la Negra Noche, una muestra de la cultura afrodescendiente; pero tanto en esta como en el Festiafro la sensación que queda es que estos son eventos dirigidos a los paisas. La clave está en la potencia del reconocimiento.

El San Pachito no solo es la reterritorialización como respuesta a la idea unívoca de la ciudad de Medellín, es la desterritorialización de una práctica que toma forma en Quibdó y es reterritorializada con otros fines, otras posibilidades, otras características y otros diálogos en Medellín. 
Figura 3. Recorrido del desfile «Entre bullas y tamboras».

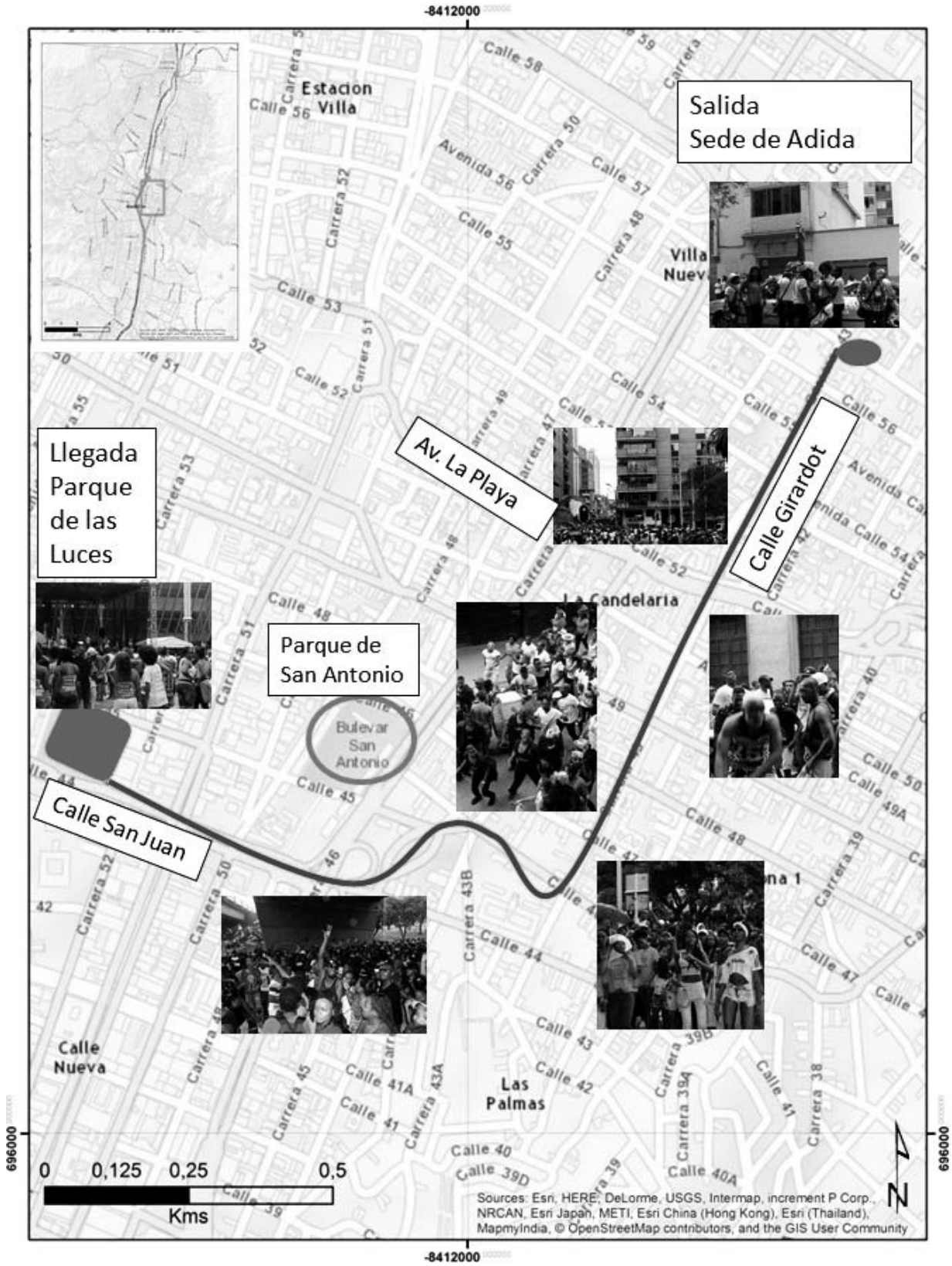

Elaboración: Ana María Restrepo Rodríguez, 2016. 
La antropóloga Sonia Serna (2013) ha relatado cómo, para los paisas que residen en Quibdó ${ }^{14}$, el San Pacho es una fiesta religiosa que dura como dos meses - una de esas semanas completa los negocios se cierran y los niños no van al colegio-, en la que poco se reza, se bebe mucho y se baila "para desentenderse de todo tipo de responsabilidad» (p. 96). Recuerdo que la primera vez que asistí al San Pachito (2015), camino al desfile, escuché decir: "es como una marcha», "esa es la cosa esa de los negros». Pero en el año 2016 vi algunos extranjeros y un par de jóvenes hippies dentro del desfile que destacaban por la diferencia en su color de piel. Yo también sobresalía, por mi color de piel, mi ropa y mi cabello; pero tenía una identificación del comité organizador, que me permitía escabullirme del baile y gracias a la cual muchos paisas no afrodescendientes se me acercaban a preguntarme de qué se trataba lo que estaba pasando. Cuando le expliqué a una mujer de unos cincuenta años que esto era el desfile de las fiestas de san Pacho de Medellín, exclamó: «¡Ay, qué belleza, qué es esta dicha!» y siguió observando y grabando con su cámara. Que cause admiración —aunque su incomprensión y desconocimiento sean amplios - indica que paulatinamente el desfile se abre camino a través de las identificaciones hegemónicas de la ciudad.

El recorrido mismo es una línea que va trazando las diferencias y las relaciones entre nosotros-ellos-ustedes. Dice Bhabha (2013) que el reconocimiento de la identidad y de la diferencia «es tanto un problema de epistemología e historia como una cuestión perceptual y fenomenológica relacionada con cómo vemos y desde dónde miramos» (p. 84). He ahí lo representativo de los posicionamientos en el desfile: quiénes observan y quiénes se movilizan. Aquellos que bailan y se mueven en comunidad por el centro de la ciudad están movilizando la idea de la

14 Valga aclarar que, tal como lo señala Serna en su tesis, lo paisa en Quibdó es todo aquello que no sea lo negro. Paisas son todos los otros habitantes de la ciudad que tienen otro color de piel y cuya procedencia es externa. Pero Serna trabaja solamente con un grupo particular de paisas-antioqueños, los provenientes del municipio de Santuario, Antioquia. 
identidad afrodescendiente en Medellín y desde esa manifestación cultural urbana muestran una ciudadanía diferente.

En Mil mesetas, Deleuze y Guattari (2004) señalan que, dado que el territorio se construye por el movimiento, es funcional y expresivo (pp. 322-328). Así, esta fiesta constituye una narrativa sobre la territorialización colectiva, que es útil para configurar las relaciones simbólicas con el espacio; sobre todo, permite dar cuenta de los proyectos y las acumulaciones de tradición sobre la ciudad y, en esa medida, aportar a la percepción de un espacio propio que va más allá de la escala micro del barrio o la calle. Se trata de recoger el sentido de SER afrodescendiente EN Medellín.

Entre la bulla y la brincadera, el San Pachito es ejercicio estratégico de territorialización de la identidad. En el campo geográfico, se toma el centro de la ciudad y hace visible el encuentro de una comunidad específica. En el campo de lo político, es acción de disputa de significados tanto de lo afrodescendiente en Medellín como de la unidad identitaria de la ciudad. En el interior de lo afrodescendiente, se convierte en proceso de transmisión de arraigos y en lugar de interrelaciones. También interpela a sus sí mismos y a sus otros (participantes y observadores), con lo cual moviliza la idea de una ciudadanía diferenciada.

Esta condición de movimiento hace que lo cultural no esté aislado de lo político, por el contrario, por su impacto en el espacio público y la multiplicidad de lo que enuncia, constituye la espacialización de un momento político de diferencia cultural. Con esto, el ruido se expande y se moviliza desde los puntos de encuentro a la calle y a la relación con la institucionalidad.

\section{La movilización: entre la fiesta y la multiterritorialidad}

El 21 de mayo de 2008 parecía ser día de San Pachito en Medellín. Afrodescendientes de cerca de cincuenta organizaciones sociales marcharon 
desde el parque San Antonio hasta la plazoleta de La Alpujarra (Centro Administrativo Departamental y Municipal) al ritmo de la canción «La vamo' a tumbar», una de las canciones de chirimía más famosas en todo el país. Pero no era la fiesta de San Pachito. Cantaban y gritaban en el Día de la Afrocolombianidad para conmemorar la abolición de la esclavitud (21 de mayo de 1851) y exigir reparación histórica, pues muchas de las condiciones de subalternidad de las poblaciones negras $\mathrm{y}$ afrodescendientes en el mundo tienen que ver con esta marca de la esclavitud.

La marcha de 2008 es una de las movilizaciones memorables del movimiento social afrocolombiano en Medellín. Marino Rentería me decía que el triunfo en la convocatoria tal vez se debía al concierto organizado para cerrar el día de movilización, ya que se presentaban los músicos Jackson Mosquera (participante en el reality de televisión el Factor $\mathrm{X}$, donde precisamente hizo famosa «La vamo' a tumbar», y vocalista del grupo Saboreo, creador de dicha canción) y el cantante de salsa (quibdoseño) Hansel Camacho. Su éxito se debió entonces a la utilización de una práctica cultural (la chirimía, el bunde) para articular a la comunidad, tal como se hace en el San Pachito.

En Colombia, las acciones de protesta de la comunidad afrodescendiente son pocas, debido a que las organizaciones o han aprendido a hacer uso de mecanismos institucionales o simplemente no ven su utilidad. Los líderes con los que hablé del tema siempre explicaban que esta situación se debía a la desidia y a la falta de información y de formación política o de sentido de comunidad. Doña Deyanira (Red de Mujeres Kambirí), por ejemplo, insistía en que no creía en el negro desunido; que aquel que actuaba de modo individual no tenía en su sangre las tradiciones ancestrales de la vida en comunidad o las negaba. Como se vio en el apartado anterior, el ejercicio de lo comunitario afrodescendiente tiene uno de sus momentos políticos en lo cultural. Esto no supone una separación de la cultura y la política, pero sí muestra que en algunos casos esa relación debe ser intencionalmente señalada. 
La movilización étnica en Colombia estuvo por mucho tiempo asociada a las luchas por la tierra. En ese sentido, el campesinado se veía como un bloque del que hacían parte negros e indígenas, lo cual se manifiesta hasta los procesos de demanda de reconocimiento de lo afrodescendiente en la década de los ochenta. Pero, aunque el movimiento campesino colombiano tiene una fuerte tradición de protesta, estos aprendizajes no parecen replicarse en las comunidades negras. Lo mismo pasó con las luchas cívicas, que recogían muchas de las luchas por mejores condiciones de vida y derecho a la ciudad de los que después serían sectores identitarios (LGBTIA, mujeres, étnicos).

Es importante señalar que, según el historiador Mauricio Archila (2008), la conquista de las identidades étnicas en Colombia tuvo un obstáculo grande: el peso de los análisis de clase. Para el autor, «el marxismo, al identificar conflictos de clase con étnicos, desconoció que los segundos eran históricamente anteriores a los primeros» (p. 403).

Valga aclarar que fueron los indígenas los que iniciaron este proceso de autonomía (de la mirada de clase) en la movilización, incluso cuando hacían parte del movimiento campesino: El Consejo Regional Indígena del Cauca (CRIC), una de las organizaciones más importantes del movimiento indígena colombiano (sino la más importante), de carácter regional pero con impacto nacional, «surgió en el momento de auge de las luchas campesinas a principios de los setenta y al abrigo de la ANUC [Asociación Nacional de Usuarios Campesinos], pero rápidamente exigió el respeto de las particularidades culturales de los indígenas del Cauca» (p. 403).

Los indígenas, además de reclamar los derechos sobre territorios ancestrales (la estrategia de recuperación de haciendas durante los setenta y ochenta fue sistemática y exitosa en términos de la visibilización de sus reclamaciones identitarias), se disputaron una y otra vez el poder de decisión sobre políticas que el gobierno central consideraba que les beneficiaban, pero que no eran ni consultadas ni construidas con 
las comunidades. Oscilaban así entre la clase y lo étnico, hasta ir conformando un movimiento social diferenciado, que no negaba las condiciones de clase, pero que las interpretaba desde sus necesidades particulares.

El movimiento afrocolombiano tuvo una larga historia de reivindicación discursiva sobre la identidad (a través de los círculos de intelectuales, publicaciones, celebraciones de lo negro y organizaciones estudiantiles), pero poco se apropió de los espacios públicos para disputar realmente cuestiones como su autonomía o derechos diferenciados para esta población.

A diferencia del reconocimiento de la ancestralidad de las poblaciones indígenas en ciertos territorios, las poblaciones negras y afrodescendientes no contaban con esta legitimación ni siquiera en los libros de historia. Así, su proceso de lucha social por los derechos políticos y étnicos no tuvo un sustento territorial o por lo menos no era visto en esos términos. Tal vez de ahí surge el hecho de que sus primeras acciones pasaran por lo discursivo o que se articularan a las luchas por derechos de comunidades más amplias (campesinas o cívicas) y que solo hasta la gestación de la Constitución de 1991 se reconocieran oficialmente (legalmente) los territorios colectivos de comunidades ancestralmente asentadas, sobre todo, en el Pacífico colombiano.

Sin embargo, a pesar de estos tropiezos, en Colombia existe un movimiento social afrocolombiano. Se entiende movimiento social como «aquella acción social colectiva permanente, orientada a enfrentar condiciones de desigualdad, exclusión o injusticia y que tiende a ser propositiva en contextos espacio-temporales determinados» (Archila, 2008, p. 74). En otras palabras, es aquella forma de la acción social colectiva que responde a un contexto de conflictos sociales (en todas sus dimensiones, no solo la económica), construye a un adversario (que se concibe como el causante o quien tiene la solución a sus demandas) y propende por el diálogo y la negociación con este (en lugar de la imposición por la fuerza o la eliminación del adversario, lo que lo diferencia 
de los movimientos armados). Esta es una forma de expresión pública colectiva en la que se hace evidente la red de conflictos sociales y los poderes implicados en la misma.

En esos términos, el movimiento social afrocolombiano, a pesar de no ejercer usualmente acciones de protesta social ${ }^{15}$, sí ha ido constituyendo un proceso sostenido de reivindicación de derechos sustentados en la protección de su identidad, frente a las políticas o el desconocimiento estatal y a la interacción cultural. En Medellín este proceso no es de larga duración, pero una mirada a sus pocas protestas permite entender no solo las condiciones particulares del habitar el espacio urbano por parte de la población negra y afrodescendiente, sino sus posibilidades de reconocimiento y sus necesidades.

Edward Soja (2008) habla de cómo los espacios creados por la complejidad (y multidimensionalidad) de la globalización se convierten en lugares estratégicos para la formación de identidades y de demandas que transforman estos espacios. Dichas demandas «son "prácticas situadas” que están en consonancia con aquellos "espacios de la diferencia” teorizados como (...) “espacios intermedios” o márgenes» (p. 331).

Dichos movimientos (urbanos) son movimientos socioespaciales ${ }^{16}$, porque sus demandas están localizadas, tienen como objetivo ampliar y profundizar el derecho a habitar la ciudad en condiciones dignas y nutren estos espacios con la politización radical del lugar. De este modo, el recurso culturalmente estratégico para convocar a la población afrocolombiana, en la conmemoración de la abolición de la esclavitud, tal vez dice mucho de las desarticulaciones comunitarias (de la anulación de lo negro a partir de su dispersión) que tienen acento en la ciudad de

15 Los registros en la Base de Datos de Luchas Sociales de Cinep son mínimos y, cuando pregunté por esto a líderes y lideresas, reconocieron su poca movilización en comparación con movimientos como el indígena y el campesino.

16 Más allá de lo que señala Bernardo Mançano de que todo movimiento social es socioespacial, porque se desarrolla en el espacio. 
Medellín. Pero, a su vez, es también un recuerdo de lo que está en la base de la movilización étnica en Colombia: la disputa por la diferencia.

Uno de los procesos de organización y movilización social más relevantes de los últimos años de la población negra y afrodescendiente de Medellín ha sido el que se ha gestado alrededor de la defensa chocoana de Belén de Bajirá. Este corregimiento es, según desde donde se hable, de Riosucio (Chocó) o Mutatá (Antioquia). En términos de delimitación geográfica pertenece a Chocó; así lo corroboró el Instituto Geográfico Agustín Codazzi en informe del mes de febrero de 2016. Sin embargo, Antioquia reclama la inversión que ha hecho en ese territorio y la disputa tendrá que ser definida en el Congreso de la República. Bajirá cuenta con dos escuelas, dos centros de salud y dos estaciones de policía, una por cada departamento. En cada escuela, por ejemplo, se entona un himno departamental diferente.

El conflicto por Bajirá hace parte de las históricas disputas por las relaciones de explotación que han establecido los antioqueños con el territorio chocoano en torno a la minería, la agricultura, la industria maderera, entre otros. De hecho, parte del conflicto tiene que ver con los yacimientos de coltán, uranio, oro y cobre en el subsuelo. La defensa de Antioquia dice que la inversión da derecho de propiedad.

Las movilizaciones de los chocoanos residentes en Medellín no son nuevas: en febrero del 2009, un accidente en la carretera Medellín-Quibdó, por las malas condiciones de la vía, cobró la vida de diez personas. Luego de este accidente, la comunidad chocoana residente en Medellín y otros medellinenses solidarios marcharon por el centro de la ciudad para exigir al gobierno nacional mayor inversión y desarrollo para el departamento de Chocó. Muchas de las víctimas eran afrodescendientes.

Años más tarde, el 14 de mayo de 2012, en la Asamblea Departamental de Antioquia se organizó un plantón para exigir la renuncia del diputado Rodrigo Mesa, quien en una sesión de la Asamblea comparó 
la inversión en Chocó con referencias escatológicas ${ }^{17}$. No todos los manifestantes eran chocoanos, pero sí afrodescendientes. El comentario de Mesa más que una agresión territorial era la representación de los imaginarios racistas que explican en parte las condiciones de subalternidad y subdesarrollo de dicho departamento y de la población afrodescendiente en Colombia. Sus declaraciones fueron la respuesta a la propuesta del gobernador de Antioquia de abrir una notaría en Chocó, dadas las fluidas redes comerciales y de movilidad entre ambos departamentos. Esta acción se recuerda porque logró convocar afrodescendientes que no hacían parte del movimiento o de otras formas de organización colectiva.

La territorialización de la identidad afrodescendiente en un espacio en el que se hace parte de la minoría es un proceso de redefinición de la pertenencia. Algunos de estos procesos están orientados a la etnicización de la identidad, otros a la activación de territorialidades superpuestas. En el caso de muchos de los afrodescendientes que hacen parte de las colonias, independientemente de sus clases sociales, la territorialización en Medellín no supone desterritorialización de sus lugares de origen. Por el contrario, Medellín se convierte en el lugar ideal para «mover cosas» por su tierra, como pasa en el caso de Belén de Bajirá.

\section{El Centro de Integración Afrodescendiente: la lucha por lo público}

Medellín es para la comunidad afrodescendiente que allí habita un espacio concebido para la acción política identitaria. Ha dejado de ser una ciudad refugio, una ciudad de tránsito o una ciudad para la formación educativa y la ocupación laboral y ha pasado a ser una ciudad para habitar de un modo distinto los ámbitos rurales, los espacios del

17 Literalmente dijo: «la plata que uno le mete al Chocó, eso es como meterle un perfume a un bollo». Para ampliar la información, véase: https://www.youtube.com/ watch? $\mathrm{v}=$ mnOacy7vi-k 
Pacífico colombiano o las otras ciudades andinas. Tal vez, lo que se va constituyendo es un modo afromedellinense de ser y vivir en la ciudad, que no implica, en el caso de las colonias, dejar de ser de sus lugares de origen, pero tampoco niega la existencia de la población negra y afrodescendiente de Medellín.

En este contexto vuelve a tomar relevancia la disputa por el lugar. Entre el ir y venir, entre el proceso de poblamiento del espacio urbano y la disputa por el territorio a través del sentido de lugar, los sitios de encuentro siguen teniendo un papel fundamental. Existe un espacio que no está bajo la tutela de una organización y se extraña como casa: el Centro de Integración Afrodescendiente, antes Casa Afro.

Inaugurado el 15 de diciembre de 2014 por el alcalde de la ciudad, Aníbal Gaviria, el Centro de Integración Afrodescendiente es un edificio gris con salones de ensayo, auditorio y las oficinas de la Unidad de Etnias de la Alcaldía. En su centro hay un patio cubierto; de una de sus paredes cuelga un mapa de África con las rutas de la esclavitud hacia América. Durante mi estadía en el trabajo de campo, se organizaron exposiciones de fotografía del conflicto armado, de liderazgos afros en la ciudad («Medellín ciudad afro») y de pintura africana. Este lugar, representa las ganancias y pérdidas (simbólicas y materiales) de la organización afrodescendiente de Medellín y sus horizontes de expectativa sobre la ciudad.

El Centro de Integración, ubicado en el barrio Prado, barrio patrimonial de Medellín localizado justo al norte del centro de la ciudad, se construyó sobre la vieja Casa Cultural Afro, una casa típica de mitad del siglo $\mathrm{Xx}$, con tres habitaciones y un salón en el que se celebraban reuniones, clases de danza y ensayos de grupos musicales, constantemente interrumpidos unos por otros, porque no había insonorización. En el nuevo edificio, también las reuniones en el Salón de Conferencias son interrumpidas por los ruidos de la calle y el calor hace muy difícil que la gente se concentre en las largas asambleas. 
Según Marino Rentería, el dinero para la antigua casa fue gestionado por el expresidente Álvaro Uribe Vélez cuando fue alcalde encargado de la ciudad: «lo que queríamos era una casa para expresar lo cultural y rescatar las tradiciones» (entrevista, febrero 19 de 2016).

En la actualidad, el Centro representa más que un lugar útil para las asambleas del Espacio Autónomo, es la representación física de la necesidad de las luchas por el espacio urbano. En primer lugar, porque al estar allí localizadas las oficinas de la Unidad de Etnias se ha quitado el derecho de propiedad comunitaria sobre este espacio; incluso, hasta hace muy poco, su horario de funcionamiento correspondía a los de las oficinas de atención pública. Por otro lado, se resiente que la construcción no evoque las tradiciones afrocolombianas. A excepción del mapa de la diáspora africana, o de las exposiciones temporales, la forma arquitectónica podría ser funcional a cualquier institución o grupo poblacional. Decía Marino Rentería: «¿cómo nos representa la parte étnica? Yo insistí mucho en que por lo menos dejaran los murales de la otra [la casa anterior], pero no les importó, el diseño ya estaba decidido y no pudimos pelear nada» (entrevista, febrero 19 de 2016). Una construcción gestionada para los indígenas usualmente tendría una estructura arquitectónica que represente las malocas; este Centro ni siquiera tiene huellas del lugar que fue para las organizaciones y asociaciones culturales de la comunidad afrodescendiente de Medellín hasta antes del 2014.

Si bien la asignación de recursos para comprar este lugar fue un gesto de reconocimiento a la ciudadanía afrodescendiente y la materialización de su espacio de participación ciudadana, dicho reconocimiento también significa la asignación de los espacios y marcos de disputa. Su nombre es muy diciente: una casa para que los afrodescendientes se integren, bien sea la integración entendida como un sitio de encuentro, reconocimiento y socialización, o la integración a un proyecto más amplio de ciudadanía orientado por la administración municipal. De hecho, en la ruta de co-creación del Plan de Desarrollo para el periodo 
2016-2019, en la reunión de la Comuna 10 (que cubre el centro de la ciudad y algunos barrios prácticamente integrados al mismo), un grupo de la tercera edad (no afrodescendiente) pedía dotación para el Centro de Integración, pues allí practicaban actividades físicas. Esta solicitud llamó la atención de quienes conocíamos el lugar (otros activistas afrodescendientes presentes en la jornada), porque hablaba de la apropiación de ese espacio como público y de los procesos de comunicación ciudadana o, en palabras de Jordi Borja (2013), del «espacio público como instrumento de redistribución social, de cohesión comunitaria, de autoestima colectiva» (p. 29).

El Centro de Integración fue uno de los lugares centrales de mi trabajo de campo. Allí asistí a las múltiples reuniones del Espacio Autónomo, conocí líderes afrodescendientes barriales y participé en una lectura en clave afrodescendiente del Plan de Desarrollo propuesto por Federico Gutiérrez (alcalde Medellín en el periodo 2016-2019). En todos estos escenarios fui entendiendo que este lugar representaba su territorio colectivo en la ciudad y a la vez una de las caras urbanas de la etnicidad: la del despojo y el desconocimiento.

En este punto es importante recordar que la Ley 70 de 1993 dotó de herramientas de propiedad colectiva de la tierra a los procesos organizativos de las comunidades negras y afrodescendientes rurales que conformaran Consejos Comunitarios. Esta herramienta legal fue fundamental para los afrocolombianos que estaban viendo amenazada su permanencia ancestral en los territorios, principalmente de la región del Pacífico colombiano; sin embargo, no contempló las condiciones de la población urbana. Un lugar como el Centro representaría esa propiedad: una ganancia territorial concreta con impacto político.

En las reuniones a las que asistí, pude observar que el Centro era un espacio de reconocimiento del afromedellinense como sujeto político: allí llegaban los funcionarios a buscar a las organizaciones, y allí sus líderes se sentían con el poder de la interlocución, pues estaban en sU 
casa. Este es un espacio en el que son escuchados. No ha sido relevante en términos de movilización contenciosa, pero sí lo ha sido como escenario de mediación, de trabajo organizativo y de gestión cultural. En ciudades que cada vez más deben reconocer su multiculturalismo, la forma en que un espacio se convierte en público a través de su identificación como referente de un grupo poblacional habla de las múltiples tramas que entretejen lo urbano: intercambio y comunicación.

Si «la ciudad es ante todo el espacio público, [y] el espacio público es la ciudad» (p. 353), como nos dice Borja, entender el Centro de Integración Afrodescendiente como espacio público permitiría concretar la producción social de un espacio de ciudadanía, el punto de llegada (pero no final) de ese largo proceso de la historia afrodescendiente en Medellín. Dice Lefebvre (2013):

Un grupo, una clase o una fracción de clase no se constituyen ni se reconocen como «sujetos» sino generando (produciendo) un espacio. Las ideas, las representaciones y los valores que no logran inscribir en el espacio engendrando (produciendo) una morfología apropiada, se marchitan en meros signos, se resuelven en narraciones abstractas y se transfiguran en quimeras. (p. 445)

\section{Cierre}

En este recorrido por la memoria de la territorialización de la identidad afrodescendiente en Medellín, se han identificado espacios y actores en disputa. En dichos espacios, unos perdidos y otros vigentes, confluyen trayectorias individuales, discursos políticos, historias de reivindicación en distintas escalas (nacional e internacional), evocaciones sobre una comunidad negra preexistente en Medellín, a la vez que «mitos fundacionales» de sus luchas y articulaciones con procesos globales económicos. Dichos espacios se constituyeron en lugares de una política de la proximidad entendida como la manera en que se negocian 
«a través de las diferencias y entre ellas, el implacable hecho espacial del terruño compartido» (Massey, 2013, p. 32).

Desde estos lugares y con sus actores se fue haciendo posible la territorialización a partir de la diferencia en Medellín. Son lugares de significación para la identidad afrodescendiente y a la vez pueden significar experiencias de proximidad para la identidad mestiza; es decir, representan «el reconocimiento del sujeto como "mismo y otro"» (Bhabha, 2013, p. 25).

Acostumbrados a moverse (bien sea porque son relocalizados en ciertos lugares, porque recorren la ciudad haciéndose un espacio, porque marcan el centro con el recorrido de la fiesta o porque se movilizan como comunidad que disputa sus derechos sobre el territorio), los afrodescendientes de Medellín no solo demandan su reconocimiento, sino que ponen en tensión los discursos sobre la identidad con los reclamos frente a la materialidad de los recursos que se invierten en su población y las relaciones de verticalidad que regulan su capacidad de acción. En otras palabras, se desplazan de los lugares sociales que les han sido asignados para hacerse presentes en los que sí consideran suyos, que son múltiples y diferenciados. De este modo, disputan también las memorias y las historias de la ciudad.

\section{Adenda: Entre la innovación y el racismo}

En el mes de marzo de 2016, Medellín fue galardonada con el Lee Kuan Yew World City Prize, «el nobel del urbanismo». Según el jurado:

Medellín es una ciudad que ha pasado de ser notoriamente violenta a una que está siendo un modelo para la innovación urbana en un lapso de solo dos décadas. Hoy en día, es una ciudad que celebra la vida, firme en su compromiso de crear un mundo más justo, más humano, más libre y más feliz para sus habitantes (...) Las soluciones creativas y no convencionales, el sistema de transporte masivo, el primer teleférico del mundo, parques 
biblioteca y escaleras mecánicas urbanas, que mejoran la movilidad en los barrios montañosos, ganaron una mención especial en el año 2014. Desde entonces, la ciudad ha seguido su incesante búsqueda de la equidad social, la competitividad y la sostenibilidad. (El Espectador, 2016)

No obstante, como escuché en una reunión entre organizaciones sociales y funcionarios de la alcaldía: «la ciudad innovadora que anda buscando premios afuera, no respeta adentro» (Notas de campo, 29 de enero de 2016). En el mes de junio del mismo, en las redes sociales se hizo viral un video de Facebook, en el que Mareleyne Lozano ${ }^{18}$, mujer afrodescendiente, denunció ser víctima del racismo en un bus de transporte urbano: "ide verdad usted cree que se van a sentar a su lado? », le dijo una mujer que le exigía que diera su asiento a una pareja mayor. Nadie, en todo el trayecto, quiso compartir asiento con ella. Su indignación la llevó a convocar a la población negra a acciones de resistencia en el transporte urbano (\#Nodoymiasiento) y a señalar que, aunque nunca había hecho parte de ningún proceso político, ahora podía denunciar el racismo de la ciudad más innovadora.

Avergonzados tienen que sentirse de que, viviendo en la ciudad que se supone que es la más innovadora del mundo, en una ciudad que es pluriétnica, aún creen que son mejores que otros. Avergonzados se tienen que sentir, que siendo la ciudad más educada, se nota que no han tomado un libro y no se han enterado de que ellos blancos no son.

Cierro con estas palabras de Mareleyne, porque en ellas y en su relato se recogen los retos para el movimiento afrocolombiano en Medellín: seguir disputando el reconocimiento y con ello las otras memorias (unas dolorosas y otras de resistencia) de su ciudad. 


\section{Bibliografía}

Alcaldía de Medellín (1676). Acta sobre petición de procurador general, f. 78v79v. Medellín: Archivo Histórico de Medellín, Fondo Concejo de Medellín, Colonia.

Alzate Quintero, Gustavo Andrés (2013). A falta de Echavarrías buenos son Escobares. Urbanización y narcotráfico en Medellín 1977-1987 (El caso del antiguo basurero municipal). Trabajo de grado para optar al título de Historiador. Departamento de Historia, Facultad de Ciencias Humanas. Medellín: Universidad de Antioquia.

Anderson, Benedict (1993). Comunidades imaginadas. Reflexiones sobre el origen y la difusión del nacionalismo. México D. F.: Fondo de Cultura Económica.

Antonsich, Marco (2010). Rethinking territory. En: Progress in Human Geography, 3(35).

Archila, Mauricio (2008). Idas y venidas, vueltas y revueltas. Protestas sociales en Colombia 1958-1990. Bogotá: Instituto Colombiano de Antropología e Historia (Icanh), Centro de Investigación y Educación Popular (Cinep).

Bhabha, Homi (2002). El lugar de la cultura. Buenos Aires: Manantial.

Bhabha, Homi (2013). Nuevas minorías, nuevos derechos: notas sobre cosmopolitismos vernáculos. Buenos Aires: Siglo Veintiuno.

Borja, Jordi (2013). Espacio público y derecho a la ciudad. En: Ramírez Kuri, Patricia (coord.), Las disputas por la ciudad: espacio social y espacio público en contextos urbanos de Latinoamérica y Europa. México: Universidad Nacional Autónoma de México, Miguel Ángel Porrúa.

Cabildo de Medellín (1875). Celebración del 2. ${ }^{\circ}$ Centenario de la Fundación de la Villa de Medellín. Medellín: Imprenta del Estado.

Cardona, Guillermo (2013). Dos avenidas y un parque con éxito. En: Gaviria, Pascual (ed.), El libro de los parques. Bogotá: Secretaría de Cultura Ciudadana-Alcaldía de Medellín, Universo Centro.

De Certeau, Michel (2000) [1990]. La invención de lo cotidiano. I. Artes de hacer. México D. F.: Universidad Iberoamericana, Departamento de Historia, Iteso. 
Delaney, David (2005). Territory: A short introduction. Malden, M. A.: Blackwell.

Deleuze, Gilles y Guattari, Felix (2004). Mil mesetas. París: Pre-textos.

Elden, Stuart (2010). Land, terrain, territory. En: Progress in Human Geography, $6(34)$.

El Espectador (2016). Medellín gana «El Premio Nobel de las ciudades». Recuperado de: http://www.elespectador.com/noticias/nacional/antioquia/ medellin-gana-el-premio-nobel-de-ciudades-articulo-622551

Fernández, Bernardo Mançano (2005). Movimientos socioterritoriales y movimientos socioespaciales. Contribución teórica para una lectura geográfica de los movimientos sociales. Recuperado de: http://web.ua.es/en/ giecryal/documentos/documentos839/docs/bmfunesp-5.pdf

García Sánchez, Andrés (2012). Espacialidades del destierro y la re-existencia. Afrodescendientes desterrados en Medellín, Colombia. Medellín: La Carreta, Instituto de Estudios Regionales-Universidad de Antioquia.

Haesbaert, Rogèrio (2011). El mito de la desterritorialización: del «fin de los territorios» a la multiterritorialidad. México: Siglo XXI.

Hall, Stuart (1997). Who needs «identity»? En: Hall, Stuart y Du Gay, Paul (eds.). Questions of Cultural Identity. London: Sage Publications.

Harvey, David (2014). Diecisiete contradicciones y el fin del capitalismo. Quito: IAEN.

Le Goff, Jacques (1991). El orden de la memoria. Barcelona: Paidós.

Lefebvre, Henri (2013). La producción del espacio. Madrid: Capitán Swing.

Massey, Doreen (2012a). Londres, diciembre de 2011. En: Albet, Abel y Benach, Nüria, Doreen Massey. Un sentido global de lugar. Barcelona: Icaria.

Massey, Doreen (2012b). Espacio, tiempo y responsabilidad política en una era de desigualdad global. En: Albet, Abel y Benach, Nüria, Doreen Massey. Un sentido global de lugar. Barcelona: Icaria.

Massey, Doreen (2013). Geografías de responsabilidad. En: Ramírez Kuri, Patricia (coord.), Las disputas por la ciudad. Espacio social y espacio público en contextos urbanos latinoamericanos y europeos. México: Universidad Nacional Autónoma de México, Instituto de Investigaciones Sociales. 
Maya, Luz Adriana y Cristancho Raúl (curadores) (2015). ¡Mandinga sea! África en Antioquia. Catálogo de la exposición celebrada en Medellín, del 3 de diciembre de 2013 al 3 de marzo de 2014. Bogotá: Universidad de los Andes, Facultad de Ciencias Sociales, Departamento de Historia, Ediciones Uniandes. Medellín: Museo de Antioquia.

Mayor Mora, Alberto (1996). Los artesanos de Medellín en el siglo XIX. En: Melo, Jorge Orlando (director general), Historia de Medellín, tomos I y II. Bogotá: Compañía Suramericana de Seguros.

Medellín Cívico (1984). Tercera época, 1627.

Melo, Jorge Orlando (director general) (1996). Historia de Medellín, tomos I y II. Bogotá: Compañía Suramericana de Seguros.

Mitchell, Mauricio, Sandoval, Juan de Jesús y Gallo, Nancy Elena (2011). Condiciones de vida de la población negra, afrocolombiana, palenquera y raizal en Medellín. Caracterización sociodemográfica, desarrollo humano y derechos humanos 2010. Medellín: Alcaldía de Medellín.

Mosquera Rosero, Claudia (1998). Estrategias de inserción de la población negra en Santafé de Bogotá: acá en Bogotá antes no se veían negros. Bogotá: Observatorio de Cultura Urbana, Instituto Distrital de Cultura y Turismo.

Nivón Bolán, Eduardo (2000). Conexiones urbanas: cultura, metrópolis, globalización. En: Revista Sociológica, 15(42), enero-abril.

Olivera, Patricia (coord.) (2003a). Espacio geográfico, epistemología y diversidad. México D. F.: Facultad de Filosofía y Letras, Universidad Nacional Autónoma de México.

Olivera, Patricia (2003b). Los espacios urbanos de la globalización. En: Olivera, Patricia (coord.), Espacio geográfico, epistemología y diversidad. México D. F.: Facultad de Filosofía y Letras, Universidad Nacional Autónoma de México.

Oslender, Ulrich (2008). Comunidades negras y espacio en el Pacífico colombiano: hacia un giro geográfico en el estudio de los movimientos sociales. Bogotá: Instituto Colombiano de Antropología e Historia.

Porto Gonçalves, Carlos Walter (2001). Geo-grafías. Movimientos sociales, nuevas territorialidades y sustentabilidad. México: Siglo XXI Editores. 
Raffestin, Claude (2013). Por una geografía del poder. Zamora: El Colegio de Michoacán.

Ramírez Kuri, Patricia (coord.) (2013). Las disputas por la ciudad: espacio social y espacio público en contextos urbanos de Latinoamérica y Europa. México: Universidad Nacional Autónoma de México, Miguel Ángel Porrúa.

Sarlo, Beatriz (2005). Tiempo pasado: cultura de la memoria y primera persona. Buenos Aires: Siglo XXI Editores.

Serna, Sonia (2013). En blanco y negro. Paisas y chocoanos en Quibdó. Tesis de Maestría en Estudios Culturales. Bogotá: Pontificia Universidad Javeriana.

Soja, Edward (2008). Postmetrópolis. Estudios críticos sobre las ciudades y las regiones. Madrid: Traficantes de Sueños.

Tuan, Yi-Fu (1977). Space and place. Minneapolis y Londres: University of Minnesota Press.

Uribe Ángel, Manuel (1892). Colón, América, Medellín. Medellín: Imprenta del Departamento.

Velásquez, Rogerio (2010). Ensayos escogidos. Colombia: Ministerio de Cultura (Biblioteca de Literatura Afrocolombiana, tomo XVII).

Villa, William (1989). San Francisco de Asís o la poética de la calle. En: Boletín cultural y bibliográfico, 19(26). Bogotá: Banco de la República.

Wade, Peter (1997). Gente negra, nación mestiza. Dinámicas de las identidades raciales en Colombia. Bogotá: Ediciones Uniandes. 